\title{
Clinical Usefulness of X-Ray Findings for Non-specific Low Back Pain in Korean Farmers: FARM Study
}

\author{
Eun Kyoung Kang, MD, PhD ${ }^{1}$, Hee-won Park, $\mathrm{MD}^{1,2}$, Sung Hyun Kim, MD, PhD ${ }^{3}$, Sora Baek, MD, $\mathrm{PhD}^{1}$
}

\begin{abstract}
${ }^{1}$ Center for Farmers' Safety and Health and Department of Rehabilitation Medicine, Kangwon National University Hospital, Chuncheon; ${ }^{2}$ Gangwon-Do Rehabilitation Hospital, Chuncheon; ${ }^{3}$ Human Medical Imaging and Intervention Center, Seoul, Korea
\end{abstract}

Objective To elucidate the association between non-specific low back pain (NSLBP) and spinal X-ray findings in Korean farmers: Farmers' Cohort for Agricultural Work-Related Musculoskeletal disorders (FARM) study.

Methods A total of 835 farmers (391 males, 444 females; mean age, 56.6 \pm 7.4 years) without red-flag signs of specific LBP were recruited. Presence of LBP more than one week or once a month with more than moderate degree of pain severity during the last year was assessed with a binary questionnaire (yes or no). Spinal degenerative changes were classified into disc height change (DHC) of L4-5 and L5-S1 (grade 0-5) and osteophyte formation of L5 (grade 0-5) by a radiologist based on X-ray findings. Additionally, spondylolisthesis, scoliosis and spondylolysis were assessed.

Results General prevalence of NSLBP was $40.7 \%$, revealing a higher incidence of NSLBP in female and younger farmers compared to male and older farmers $\left(\chi^{2}=23.3, \mathrm{p}<0.001 ; \chi^{2}=4.54, \mathrm{p}<05\right.$, respectively $)$. Among $\mathrm{X}$-ray findings, DHC (L5-S1) grade 4 revealed significantly higher relative risk of NSLBP compared to grade 0 (odds ratio, 5.00; 95\% confidence interval, 2.05-12.20) after adjusting age and sex, while other X-ray findings were not associated with NSLBP.

Conclusion The NSLBP of Korean farmers was significantly related to lumbar disc degenerative changes, suggesting clinical usefulness of X-ray findings in assessing LBP in farmers.

Keywords Agriculture, Low back pain, Radiography, Osteoarthritis, Spine

Received November 21, 2016; Accepted February 6, 2017

Corresponding author: Sora Baek

Center for Farmers' Safety and Health and Department of Rehabilitation Medicine, Kangwon National University Hospital, 156 Baengnyeong-ro, Chuncheon 24289, Korea. Tel: +82-33-258-9100, Fax: +82-33-258-2146, E-mail: sora.baek@kangwon.ac.kr

ORCID: Eun Kyoung Kang (https://orcid.org/0000-0001-5315-1361); Hee-won Park (https://orcid.org/0000-0002-7434-6675); Sung Hyun Kim (https:// orcid.org/0000-0002-4142-3021); Sora Baek (https://orcid.org/0000-0003-3404-6202).

@ This is an open-access article distributed under the terms of the Creative Commons Attribution Non-Commercial License (http://creativecommons.org/ licenses/by-nc/4.0) which permits unrestricted noncommercial use, distribution, and reproduction in any medium, provided the original work is properly cited. Copyright $\odot 2017$ by Korean Academy of Rehabilitation Medicine 


\section{INTRODUCTION}

Low back pain (LBP) is the most frequent musculoskeletal symptom (MSD) among farmers, with a lifetime prevalence of $75 \%$; LBP resulted in sick leave and reduced productivity $[1,2]$. Among farmers, LBP pain was most frequent (63.8\%) compared to other body sites [3]. This LBP may be classified into specific LBP, that may result from serious spinal pathologies (e.g., malignancies, infections, fracture, and radicular syndrome), and nonspecific LBP (NSLBP), representing most cases of LBP and is not attributable to a recognizable specific cause $[2,4]$.

A lumbar spinal X-ray examination is frequently conducted primarily in patients with NSLBP to assess presence of degenerative, congenital, and postural abnormalities associated with NSLBP, or to exclude specific causes of LBP with various red flags, including low weight, previous history of cancer, progressive neurology, violent trauma, and fever. Examination for these specific redflag causes is conducted despite relatively low prevalence of specific LBP with further radiological evaluation (e.g., computed tomography or magnetic resonance imaging) to determine original disease course [4]. Conversely, Xray findings are often the sole objective results in assessing subjective symptoms of NSLBP, reflecting the need for a strategic clinical approach in lumbar X-ray examinations of NSLBP.

However, the role of X-ray examinations for determining etiology of NSLBP among farmers is unclear. In crosssectional studies of large study populations, Schepper et al. [5] and Cho et al. [6] reported significant association between NSLBP and X-ray findings with respect to lumbar degenerative changes. Meanwhile, van Tulder et al. [7] was unable to validate presence or absence of a causal relationship between radiographic findings and NSLBP.

Nonetheless, X-ray findings may provide the basis for diagnosis and management guidelines for NSLBP. We focused on elucidating the relationship between NSLBP and X-ray findings in Korean farmers as part of a strategic clinical approach: Farmers' Cohort for Agricultural WorkRelated Musculoskeletal disorders (FARM).

\section{MATERIALS AND METHODS}

This research is a cross-sectional analysis of FARM study [8], conducted by the Center for Farmers' Safety and Health at Kangwon National University Hospital. Farmers owning or renting a farm and belonging to an agricultural cooperative unit were recruited September 2013-June 2014; their occupation was secondarily verified by local representatives of the National Agricultural Cooperative Federation. This prospective cohort study was approved by the Institutional Review Board at Kangwon National University Hospital (IRB No. 2013-06-009007). All subjects provided written informed consent.

\section{Subjects}

A total 1,027 subjects were recruited for this study. Consequently, four amputees, one very low-weight individual $(37.7 \mathrm{~kg}$ ), and nine non-farming subjects (as verified by local representatives of the National Agricultural Cooperative Federation) were excluded from the study as non-farmers. Because 26 of the remaining 1,013 eligible subjects were unable to undergo X-ray, 987 subjects were available to be assessed based on radiological findings. To match the definition of NSLBP, this study specially regarded red flags as frequent signs of specific causes of LBP without considering age because farmers were generally elderly; had previous history of cancer, violent trauma, fever, and progressive neurology. Subjects with cancer history (30 patients), with a history of vertebral compression fracture (50 subjects), and with prior lumbar trauma (30 subjects) in addition to those with spinal surgery ( 42 subjects) were excluded. Finally, 835 subjects were enrolled in this cross-sectional study (Fig. 1). Their age ( $<65$ or $\geq 65$ years), sex, type of farming (rice farming, dry fields farming, greenhouses farming or orchards farming) were assessed for demographic analysis.

\section{Definition of low back pain}

The 1-year self-reported prevalence of LBP was assessed by a binary questionnaire (yes or no). The questionnaire asked participants about the duration ( $<1$ day, $<1$ week, $<1$ month, $<6$ months or $\geq 6$ months), severity (mild, moderate, severe or extremely) and frequency (daily, once a week, once a month, once in 2 or 3 months or once in 6 months) of LBP developed by the Korea Occupational Safety and Health Agency [9]. If back pain had lasted longer than 1 week or had been more frequent than once a month with more than moderate degree of pain severity, the condition was defined as presence of LBP. 


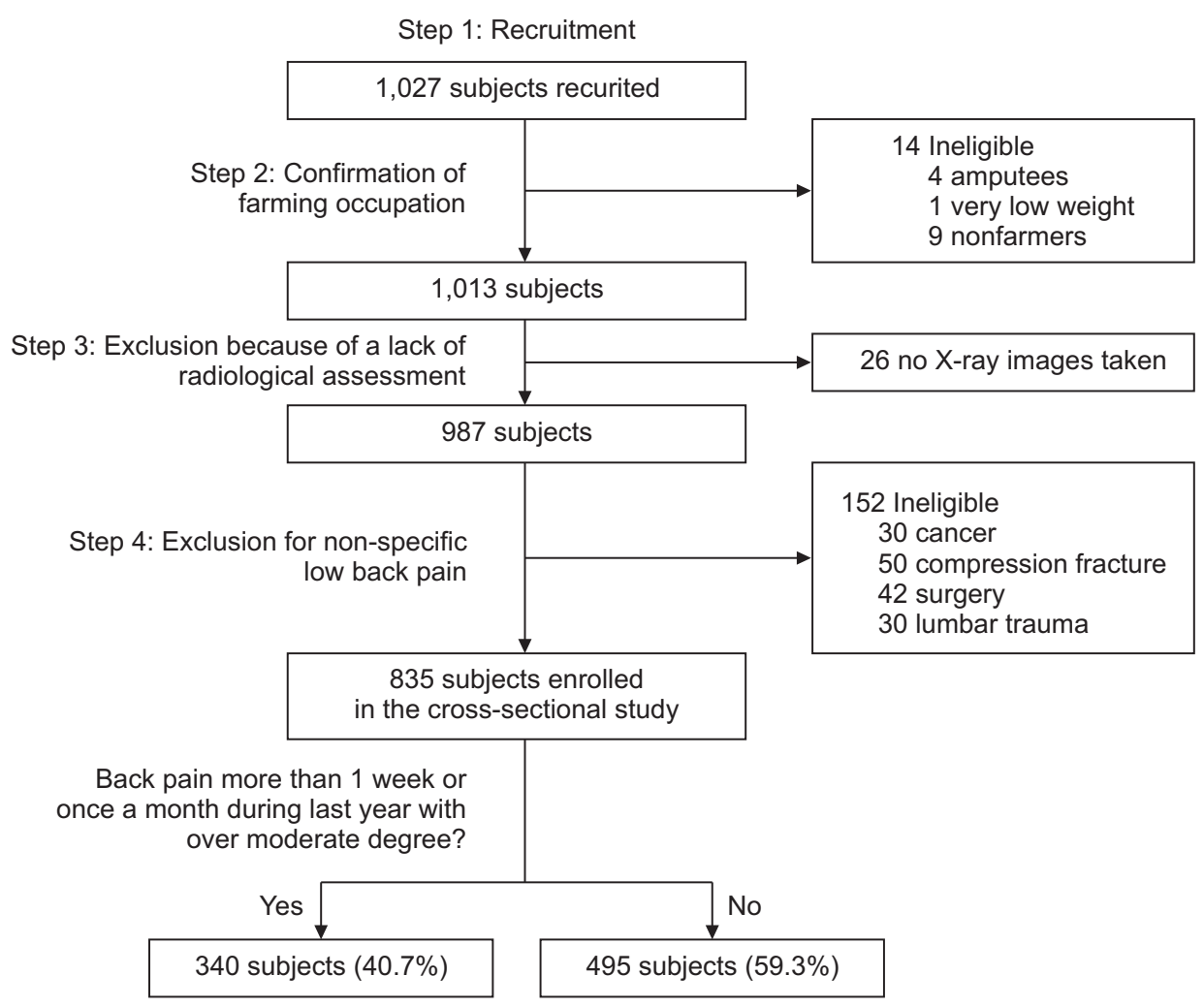

Fig. 1. Inclusion flowchart.

\section{Radiographic test}

To identify quantitative biomechanical properties of the spine, two plain X-ray images of the lumbosacral spine at the neutral posteroanterior and lateral views were assessed per subject, and disc height loss and osteophyte formation of lower lumbar segment as spinal degenerative signs were graded individually by a specialized expert radiologist with blind manner based on X-ray findings described by Mimura et al. [10] with some modifications. DHC was evaluated by relative percent of disc height of L4-5 and L5-S1 compared with the height of just above level if it was normal. If disc height of just above level was not normal, DHC was compared with the empirical standard. Then, DHC was graded as 0 (normal), 1 (mild, $>75 \%$ ), 2 (moderate, $>50 \%$ ), 3 (severe, $>25 \%$ ) or 4 (very severe, $\leq 25 \%$ ). Additionally, the score for osteophyte formation of L5 was derived from the total points for osteophyte formation on eight edges of the vertebral body $(<3$ $\mathrm{mm}, 1$ point; $\geq 3 \mathrm{~mm}, 2$ points), and subsequently graded as 0 ( 0 points), 1 ( $1-4$ points), 2 (5-8 points), 3 (9-12 points), or 4 (13-16 points). Spondylolisthesis of L5 on S1, lumbar scoliosis, spondylolysis, and a history of compression fracture or lumbar surgery were also evaluated by X-ray findings.

\section{Statistical analysis}

Demographic data and X-ray findings were classified as categorical variables and were assumed to constitute statistically independent variables for statistical analysis. Descriptive analysis was conducted to determine frequency of evaluated variables and chi-square analysis was conducted to demonstrate association between NSLBP and sex or age. Spondylolysis was excluded from the analysis because of insufficient numbers of cases $(n=5)$. Binary logistic regression analysis was conducted to evaluate association of NSLBP with X-ray findings for univariate analyses, and interaction among variables of $\mathrm{X}$-ray findings adjusting for sex and age. Odds ratios (OR) and $95 \%$ confidence interval (CI) were calculated. A pvalue of $<0.05$ was significant. All statistics were analyzed with the Statistical Package for the Social Sciences ver. 20.0 (IBM, Armonk, NY, USA).

\section{RESULTS}

Of 853 subjects ( 391 men, 444 women; mean age, $56.6 \pm 7.4$ years) participating in the study, $340(40.7 \%)$ reported NSLBP, defined as LBP more than 1 week or once a month with more than moderate degree of pain severity 
during the last year. In frequency order types of farming were: dry fields farming (39.9\%), greenhouses farming (32.6\%), rice farming (14.6\%), and orchards farming (12.9\%) (Table 1). Chi-square analysis revealed NSLBP was significantly associated with $\operatorname{sex}\left(\chi^{2}=23.3, \mathrm{p}<0.001\right)$ and age $\left(\chi^{2}=4.54, \mathrm{p}<0.05\right)$ (Table 2$)$.

Individual grades of $\mathrm{X}$-ray findings are presented in Table 3. A DHC of L4-5 and L5-S1 was observed in $23.6 \%$ and $36.6 \%$ of the subjects, respectively. The most common grade of DHC was grade 1 in L4-5 (13.5\%) and L5-S1 (18.1\%). Osteophyte formation was demonstrated in $83 \%$ of subjects; the most frequent grades were grade 1 (37.7\%) and grade $2(37.4 \%)$. Spondylolisthesis of L5 on S1 was demonstrable in $89(10.7 \%)$ and was grade I in all cases. Lumbar scoliosis was noted in 41 subjects (4.9\%). Spondylolysis was demonstrable in only five subjects and was excluded from further analysis.

According to the univariate analysis after adjusted for sex and age, DHC (L4-5, grade 4; L5-S1, grade 4) were

Table 1. Demographic characteristics of recruited Korean farmers

\begin{tabular}{|cc|}
\hline \multicolumn{1}{c}{ Variable } & Value \\
\hline Age $(\mathrm{yr})$ & $56.6 \pm 7.4$ \\
\hline Sex & \\
\hline Male & $391(46.8)$ \\
\hline Female & $444(53.2)$ \\
\hline Type of farming & \\
\hline Rice & $122(14.6)$ \\
\hline Dry fields & $333(39.9)$ \\
\hline Greenhouses & $272(32.6)$ \\
\hline Orchards & $108(12.9)$ \\
\hline
\end{tabular}

Values are presented as mean \pm standard deviation or number (\%). independent risk factors of NSLBP. Osteophyte formation and spondylolisthesis were not associated with risk factors of NSLBP. Based on subsequent multivariate analysis, DHC (L5-S1, grade 4) remained independent risk factors of NSLBP (Table 4).

\section{DISCUSSION}

This purpose of this study was to identify clinical usefulness of X-ray findings in NSLBP in Korean farmers, because even though an X-ray examination of the lumbar spine is routinely ordered for indication of NSLBP at the first visit, clinical usefulness during the diagnosis of NSLBP has not been proven. After reviewing the association between presence of LBP and X-ray findings, we found a close relationship between NSLBP and degenerative spinal change such as DHC.

Farmers are highly susceptible to LBP because agricultural activities involve exhaustive physical labor (e.g., lengthy hours, lifting, bending, twisting, pulling, pushing) that may induce spinal degenerative changes from a cumulative workload [11-13]. Van Tulder et al. [7] reported that degeneration, as defined by presence of DHC, osteophyte formation, and sclerosis, was associated with NSLBP. However, ORs were low (1.2-3.3), and the authors found no significant association between spinal degenerative changes and LBP. Torgerson and Gotter [14] reported that osteophyte formation was not associated with LBP and that spondylolisthesis occurred more frequently in symptomatic than in asymptomatic patients. Kalichman et al. [15] found that spondylolisthesis was not associated with LBP in an adult community-based population. Results of several studies were not consistent and did not consider overall X-ray findings. This study was designed to include general consideration of X-ray

Table 2. Association of non-specific low back pain with sex and age

\begin{tabular}{ccccc}
\hline \multirow{2}{*}{ Variable } & \multicolumn{2}{c}{ Presence of non-specific low back pain } & \multirow{2}{*}{$\chi^{2}$} & p-value \\
\cline { 2 - 3 } & No & Yes & 23.3 & $<0.001$ \\
\hline Sex & $266(31.9)$ & $125(15.0)$ & & \\
Male & $229(27.4)$ & $215(25.7)$ & & \\
\hline Female & & & 4.54 & \\
\hline Age (yr) & $416(49.8)$ & $266(31.9)$ & & \\
$<65$ & $79(9.5)$ & $74(8.9)$ & & \\
$\geq 65$ & &
\end{tabular}

Values are presented as number (\%). 
Table 3. X-ray findings of recruited Korean farmers

\begin{tabular}{|cccc}
\hline Variable & Male (n=391) & Female (n=444) & All (n=835) \\
\hline DHC (L4-5) & & & \\
\hline Grade 0 & $323(82.6)$ & $315(70.9)$ & $638(76.4)$ \\
\hline Grade 1 & $40(10.2)$ & $73(16.4)$ & $113(13.5)$ \\
\hline Grade 2 & $14(3.6)$ & $32(7.2)$ & $23(5.5)$ \\
\hline Grade 3 & $9(2.3)$ & $14(3.2)$ & $15(1.8)$ \\
\hline Grade 4 & $5(1.3)$ & $10(2.3)$ & $532(63.7)$ \\
\hline DHC (L5-S1) & & & $151(18.1)$ \\
\hline Grade 0 & $278(71.1)$ & $254(57.2)$ & $62(7.4)$ \\
\hline Grade 1 & $66(16.9)$ & $85(19.1)$ & $58(6.9)$ \\
\hline Grade 2 & $21(5.4)$ & $41(9.2)$ & $32(3.8)$ \\
\hline Grade 3 & $15(3.8)$ & $43(9.7)$ & $142(17.0)$ \\
\hline Grade 4 & $11(2.8)$ & $21(4.7)$ & $315(37.7)$ \\
\hline Osteophyte formation (L5) & & & $312(37.4)$ \\
\hline Grade 0 & $38(9.7)$ & $104(23.4)$ & $59(7.1)$ \\
\hline Grade 1 & $117(29.9)$ & $198(44.6)$ & $7(0.8)$ \\
\hline Grade 2 & $187(47.8)$ & $125(28.2)$ & $89(10.7)$ \\
\hline Grade 3 & $43(11.0)$ & $16(3.6)$ & $41(4.9)$ \\
\hline Grade 4 & $6(1.5)$ & $1(0.2)$ & $5(0.6)$ \\
\hline Etc. & & & \\
\hline Spondylolisthesis (grade I) & $22(5.6)$ & $32(7.2)$ & $3(0.7)$ \\
\hline Scoliosis & $9(2.3)$ & & \\
\hline Spondylolysis & $2(0.5)$ & & \\
\hline
\end{tabular}

Values are presented as number (\%).

DHC, disc height change.

findings to determine any association with LBP throughout.

In a cross-sectional lumbar magnetic resonance imaging study for machine drivers, carpenters and office workers, LBP was associated with signs of disc degeneration and sciatic pain with posterior disc bulges [16]. In this study using simple X-ray examination, DHC (L5-S1) was more common than DHC (L4-5) in Korean farmers, and DHC (L5-S1, grade 4) remained an independent risk factor of NSLBP among X-ray findings. Other X-ray findings such as osteophyte formation, spondylolisthesis and scoliosis were not associated with NSLBP. Additionally, lower spinal segments such as L4, L5 and S1 were assessed in evaluating DHC, osteophyte formation and spondylolisthesis in this study, because of their vulnerable apex area of lumbar spine to mechanical force $[17,18]$. If considering cost-effectiveness, our study found benefits of X-ray of the lower segment of the lumbar spine in identifying clinical usefulness in diagnosis and predic- tion of NSLBP.

Ozguler et al. [19] reported prevalence of LBP lasting at least one day in the previous 6 months was $45 \%$ among non-farming workers from offices, hospitals, warehouses, and airport registration sites for luggage, suggesting prevalence of LBP differs based on definition of this condition. Holmberg and Thelin [20] reported that frequency of low back issues during the year before the survey was $43.7 \%$ in a rural population, but provided no definition with respect to pain duration or frequency. Our definition for presence of LBP was back pain longer than 1 week or more frequent than once a month with more than moderate degree of pain severity during the last year. As a result, $40.7 \%$ of subjects complained of LBP after exclusion of individuals with the expected causes of specific LBP, and were subsequently defined as having NSLBP. Given the stricter definition of LBP in this study, incidence of LBP in farmers was slightly lower than in non-farmers or other farmer groups. 
Table 4. Association of non-specific low back pain with demographic characteristics and X-ray findings, adjusted by sex and age

\begin{tabular}{|c|c|c|c|c|c|c|}
\hline \multirow{4}{*}{ Variable } & \multicolumn{6}{|c|}{ Presence of non-specific low back pain } \\
\hline & \multirow{3}{*}{$\begin{array}{c}\text { No } \\
\begin{array}{c}\text { No. of cases } \\
(\%)\end{array}\end{array}$} & \multicolumn{5}{|c|}{ Yes } \\
\hline & & \multirow{2}{*}{$\begin{array}{c}\text { No. of cases } \\
\text { (\%) }\end{array}$} & \multicolumn{2}{|c|}{ Univariate analysis } & \multicolumn{2}{|c|}{ Multivariate analysis } \\
\hline & & & OR (95\% CI) & p-value & OR (95\% CI) & p-value \\
\hline \multicolumn{7}{|l|}{ DHC (L4-5) } \\
\hline Grade 0 & $401(48.0)$ & $237(28.4)$ & 1.00 & & 1.00 & \\
\hline Grade 1 & $57(6.8)$ & $56(6.7)$ & $1.51(1.00-2.28)$ & 0.05 & $1.49(0.96-2.32)$ & 0.08 \\
\hline Grade 2 & $25(3.0)$ & $21(2.5)$ & $1.18(0.64-2.19)$ & 0.60 & $1.00(0.51-1.97)$ & 1.00 \\
\hline Grade 3 & $9(1.1)$ & $14(1.7)$ & $2.32(0.97-5.55)$ & 0.06 & $1.95(0.77-4.98)$ & 0.16 \\
\hline Grade 4 & $3(0.4)$ & $12(1.4)$ & $5.57(1.53-20.31)$ & 0.01 & $3.30(0.84-12.87)$ & 0.09 \\
\hline \multicolumn{7}{|l|}{ DHC (L5-S1) } \\
\hline Grade 0 & $339(40.6)$ & & 1.00 & & 1.00 & \\
\hline Grade 1 & $83(9.9)$ & $68(8.1)$ & $1.37(0.94-1.99)$ & 0.10 & $1.30(0.88-1.92)$ & 0.19 \\
\hline Grade 2 & $34(4.1)$ & $28(3.4)$ & $1.27(0.74-2.18)$ & 0.39 & $1.26(0.7-2.26)$ & 0.45 \\
\hline Grade 3 & $32(3.8)$ & $26(3.1)$ & $1.15(0.66-2.02)$ & 0.62 & $1.08(0.6-1.95)$ & 0.79 \\
\hline Grade 4 & $7(0.8)$ & $25(3.0)$ & $5.58(2.35-13.28)$ & $<0.001$ & $5.00(2.05-12.2)$ & $<0.001$ \\
\hline \multicolumn{7}{|c|}{ Osteophyte formation } \\
\hline Grade 0 & $81(9.7)$ & $61(7.3)$ & 1.00 & & 1.00 & \\
\hline Grade 1 & $192(23.0)$ & $123(14.7)$ & $0.92(0.61-1.38)$ & 0.68 & $0.85(0.56-1.29)$ & 0.44 \\
\hline Grade 2 & $191(22.9)$ & $121(14.5)$ & $1.04(0.68-1.59)$ & 0.85 & $0.92(0.59-1.43)$ & 0.71 \\
\hline Grade 3 & $29(3.5)$ & $30(3.6)$ & $1.82(0.95-3.48)$ & 0.07 & $1.44(0.73-2.84)$ & 0.29 \\
\hline Grade 4 & $2(0.2)$ & $5(0.6)$ & $4.91(0.90-26.92)$ & 0.07 & $4.57(0.80-26.2)$ & 0.09 \\
\hline \multicolumn{7}{|c|}{ Spondylolisthesis } \\
\hline No & $444(53.2)$ & $302(36.2)$ & 1.00 & & 1.00 & \\
\hline Yes & $51(6.1)$ & $38(4.6)$ & $0.89(0.56-1.41)$ & 0.62 & $0.87(0.54-1.41)$ & 0.57 \\
\hline \multicolumn{7}{|l|}{ Scoliosis } \\
\hline No & $478(57.2)$ & $316(37.8)$ & 1.00 & & 1.00 & \\
\hline Yes & $17(2.0)$ & $24(2.9)$ & $1.77(0.93-3.39)$ & 0.08 & $1.42(0.72-2.83)$ & 0.31 \\
\hline
\end{tabular}

OR, odds ratio; CI, confidence interval; DHC, disc height change.

To verify association of demographic factors with NSLBP, chi-square analysis was conducted. Results revealed presence of NSLBP was related to younger farmers and female farmers. To validate clear association between NSLBP and X-ray findings, we adjusted results of the regression analysis of age and sex.

In general, men participate in managing heavy physical workloads, material handling, and whole-body vibration, and thus the fraction of LBP in men is higher than in women [12]. However, in this study, the fraction of LBP in women was higher than in men. If the self-reporting of LBP is considered, this finding may potentially be regarded as the result of a perceived cultural tendency of Ko- rean women to falsely claim illness. However, objective findings that women revealed a higher definite risk factor of DHC (L5-S1) with additional findings of spondylolisthesis, and scoliosis as compared to men support a higher prevalence of NSLBP in women. Korean farming work is typically labor intensive, especially for women. Women usually perform open field work on inclined farmland in a squatting position for a lengthy duration, while men operate agricultural machines in a standing position.

In addition to sexual attribution to NSLBP, a previous systematic review considering age effects on LBP reported prevalence of LBP in the geriatric population is not known with certainty but is not comparable with 
that in the younger population [21]. The 1-year incidence of first attacks of LBP was $11 \%$ among 30 -year-olds and decreased in older age groups [22]. If a farmer is older than 65 , his/her work activities may be reduced because of limited physical function, reflecting higher impact of workload on development of LBP.

The lumbar spinal structure is composed of bone, ligaments, facet joints, vertebral periosteum, paravertebral musculature and fascia, annulus fibrosis, and the spinal nerve [23], and back pain in the lumbar soft tissue is common [12]. To diagnose NSLBP, a physical examination (e.g., inspection, palpation, observation, and neuromuscular evaluation) should conducted prior to X-ray examination because of limited clinical meanings of $\mathrm{X}$ ray findings, that may function as an additive tool in primary care setting for NSLBP.

This study only focused on lumbar X-ray findings regarding NSLBP. NSLBP of Korean farmers revealed significant association with spinal degenerative changes such as DHC (L5-S1). However, to treat NSLBP effectively, establishment of a correct diagnosis at initial presentation is imperative [24]: an additive diagnostic process (e.g., detailed physical examination or obtaining patient's history) for NSLBP in the primary care setting to determine non-bony origin of pain. Further study including overall diagnostic examinations may be need in the future. DHC was determined based on empirical standard if disc height of just above level was not normal, there may be bias of personalized experiences.

In conclusion, NSLBP was significantly associated with female and younger farmers in demographic consideration, and with lumbar disc degenerative changes in objective consideration. In a clinical setting lumbar disc degenerative changes may be useful in diagnosing and setting a treatment plan in NSLBP.

\section{CONFLICT OF INTEREST}

No potential conflict of interest relevant to this article was reported.

\section{ACKNOWLEDGMENTS}

This study was supported by 2015 Research Grant from Kangwon National University and 2016 Kangwon National University Hospital Grant.

\section{REFERENCES}

1. Osborne A, Blake C, Fullen BM, Meredith D, Phelan J, McNamara J, et al. Prevalence of musculoskeletal disorders among farmers: a systematic review. Am J Ind Med 2012;55:143-58.

2. Balague F, Mannion AF, Pellise F, Cedraschi C. Nonspecific low back pain. Lancet 2012;379:482-91.

3. Min D, Baek S, Park HW, Lee SA, Moon J, Yang JE, et al. Prevalence and characteristics of musculoskeletal pain in Korean farmers. Ann Rehabil Med 2016;40:113.

4. Greenhalgh S, Selfe J. A qualitative investigation of Red Flags for serious spinal pathology. Physiotherapy 2009;95:224-7.

5. de Schepper EI, Damen J, van Meurs JB, Ginai AZ, Popham M, Hofman A, et al. The association between lumbar disc degeneration and low back pain: the influence of age, gender, and individual radiographic features. Spine (Phila Pa 1976) 2010;35:531-6.

6. Cho NH, Jung YO, Lim SH, Chung CK, Kim HA. The prevalence and risk factors of low back pain in rural community residents of Korea. Spine (Phila Pa 1976) 2012;37:2001-10.

7. van Tulder MW, Assendelft WJ, Koes BW, Bouter LM. Spinal radiographic findings and nonspecific low back pain: a systematic review of observational studies. Spine (Phila Pa 1976) 1997;22:427-34.

8. Jo H, Baek S, Park HW, Lee SA, Moon J, Yang JE, et al. Farmers' Cohort for Agricultural Work-Related Musculoskeletal Disorders (FARM) study: study design, methods, and baseline characteristics of enrolled subjects. J Epidemiol 2016;26:50-6.

9. Korea Occupational Safety and Health Agency. Questionnaire for musculoskeletal symptoms. In: Guideline for evaluation of risk factors for musculoskeletal disorders. Ulsan: Korea Occupational Safety \& Health Agency; 2003.

10. Mimura M, Panjabi MM, Oxland TR, Crisco JJ, Yamamoto I, Vasavada A. Disc degeneration affects the multidirectional flexibility of the lumbar spine. Spine (Phila Pa 1976) 1994;19:1371-80.

11. Osborne A, Blake C, McNamara J, Meredith D, Phelan J, Cunningham C. Musculoskeletal disorders among Irish farmers. Occup Med (Lond) 2010;60:598-603.

12. Punnett L, Pruss-Utun A, Nelson DI, Fingerhut MA, 
Leigh J, Tak S, et al. Estimating the global burden of low back pain attributable to combined occupational exposures. Am J Ind Med 2005;48:459-69.

13. Woolf AD, Pfleger B. Burden of major musculoskeletal conditions. Bull World Health Organ 2003;81:646-56.

14. Torgerson WR, Dotter WE. Comparative roentgenographic study of the asymptomatic and symptomatic lumbar spine. J Bone Joint Surg Am 1976;58:850-3.

15. Kalichman L, Kim DH, Li L, Guermazi A, Berkin V, Hunter DJ. Spondylolysis and spondylolisthesis: prevalence and association with low back pain in the adult community-based population. Spine (Phila Pa 1976) 2009;34:199-205.

16. Luoma K, Riihimaki H, Luukkonen R, Raininko R, Viikari-Juntura E, Lamminen A. Low back pain in relation to lumbar disc degeneration. Spine (Phila $\mathrm{Pa}$ 1976) 2000;25:487-92.

17. Berlemann U, Gries NC, Moore RJ. The relationship between height, shape and histological changes in early degeneration of the lower lumbar discs. Eur Spine J 1998;7:212-7.

18. Shao Z, Rompe G, Schiltenwolf M. Radiographic changes in the lumbar intervertebral discs and lumbar vertebrae with age. Spine (Phila Pa 1976) 2002;27:2638.
19. Ozguler A, Leclerc A, Landre MF, Pietri-Taleb F, Niedhammer I. Individual and occupational determinants of low back pain according to various definitions of low back pain. J Epidemiol Community Health 2000;54:215-20.

20. Holmberg SA, Thelin AG. Primary care consultation, hospital admission, sick leave and disability pension owing to neck and low back pain: a 12-year prospective cohort study in a rural population. BMC Musculoskelet Disord 2006;7:66.

21. Bressler HB, Keyes WJ, Rochon PA, Badley E. The prevalence of low back pain in the elderly: a systematic review of the literature. Spine (Phila Pa 1976) 1999; 24:1813-9.

22. Biering-Sorensen F. A prospective study of low back pain in a general population. I. Occurrence, recurrence and aetiology. Scand J Rehabil Med 1983;15:719.

23. Igbinedion BO, Akhigbe A. Correlations of radiographic findings in patients with low back pain. Niger Med J 2011;52:28-34.

24. Rubinstein SM, van Tulder M. A best-evidence review of diagnostic procedures for neck and low-back pain. Best Pract Res Clin Rheumatol 2008;22:471-82. 